\title{
AN EDUCATIONAL GAME IN CONSTRUCTION
}

\section{PROCUREMENT NEGOTIATION}

\author{
Pei-Ru Wang \\ National Chiao-Tung University \\ Department of Civil Engineering, No. 1001, Ta Hsueh Rd., Hsinchu 300, Taiwan \\ lulu3302@ms24.url.com.tw \\ Ren-Jye Dzeng \\ National Chiao-Tung University \\ Department of Civil Engineering, No. 1001, Ta Hsueh Rd., Hsinchu 300, Taiwan \\ rjdzeng@mail.nctu.edu.tw
}

\begin{abstract}
Project managers are frequently required to negotiate during the procurement of construction materials and drawing up of contractual agreements. Training in negotiation training requires hands-on experience and interaction with multiple parties. However, in the conventional curriculum on construction management, negotiation is taught merely through lectures and case studies. This study addressed that shortcoming by developing a portfolio negotiation game in which students play different roles and actively make decisions while proceeding through a simulated negotiation process in a competitive context. The proposed game would be the first negotiation game within the domain of the construction industry. During the pilot study, 46 students (with or without industrial working experience) played the game; the results showed an increase in learning interest, satisfaction, and effectiveness.
\end{abstract}

Keywords: Bargaining, Negotiation, Procurement, Education Game, Training, Learning Effect 


\section{INTRODUCTION}

Procurement negotiation in construction management depends strongly on experience. Currently in universities, construction management courses mostly comprise lectures without engagement in real cases. Therefore, even if students are able to grasp the essence of the lectures, their lack of hands-on experience can impede their acquisition of practical knowledge. It is not uncommon that most civil engineering graduates gain no practical experience or any relevant skills until they actually enter the field. This discrepancy between theory and practice in negotiation training suggests an inadequacy in current higher education practice. Erdem (2009) stated that case-based teaching and learning are important issues in educating students in procurement negotiation.

Brozik and Zapalska(2002) developed a portfolio game to strengthen students' abilities in making investment decisions. This training game involved a decision-supported system and the modeling of negotiators' preference and behaviors, engaging students in a dynamic market setting of possible economic and investment conditions and capital limitations, and encouraging them to collect and analyze information and make proper investment decisions thereof. Bushell(2001)discussed several advantages of game training, including building knowledge of the real world, understanding team building and personnel behavior; improving motivation, and appreciating the importance of adequate information for sound decision-making, risk assessment, and time management.

Game-based teaching has recently been widely received in construction research. Relevant applications may teach students to operate equipment such as a crane (e.g., Rounds, Hendrick, \& Higgins, 1986), construct buildings (e.g., T. \& E., 1969), or solve problems (e.g., Veshosky, 1991). Such games are either paper-based or web-based, or both. Although students are able to experiment with various roles and gain a wide range of interactions with other players, these models are rarely used, especially in procurement negotiations.

We proposed a game model that allows students to play the role of a buyer or a seller. Students are able to negotiate and compete with each other on the basis of randomly-parameterized projects released in the virtual market. Virtual players, represented by computer agents, can also participate to enhance competiveness and prevent obnoxious or illegal alliances among students. 


\section{METHODOLOGY}

Procurement negotiation in the construction industry implies a process of seeking an agreement point in a multidimensional space. Each dimension corresponds to a negotiable issue, and each issue may contain several options. Dzeng and Lin's (2004) survey identified probable negotiable issues during negotiations in construction material procurement. They also studied common options in each issue and the related preferences of contractors and suppliers. Key issues identified by Dzeng and Lin(2005) included price, payment term, payment period, advance payment, resource provision, freightage, delivery, and opportunities for extended, mass and future procurement.

Mumpower (1991) found that each negotiating party perceived the negotiable issues in a unique manner. Furthermore, perceptions of an issue might be represented by a function of judgment of utility, including weight, function forms, and organization of joint utility structure.

This study proposed a game-based training model intended to enhance students' skills in construction procurement negotiation and to provide support for the training of related strategies. The proposed model integrated several approaches: utility theory, a combination of competitive and cooperative negotiation methods, and the strategies suggested by Liang and Doong(1999).

Students who joined the game formed two groups, respectively taking the role of a constructor and a supplier. The teaching assistant played the role of a wholesaler who provided steel to the supplier. This time-constrained game was designed to attract academic students in the field of civil engineering and to help them gain practical experience through gaming. The game is divided into two phases: the first requires the supplier to purchase steel from the wholesaler through bidding; the second, the constructor to continuously negotiate, based on the project requirements, with the supplier for steel procurement. The winner of the game was the team with the highest remaining funds at the end of game.

\section{EXPERIMENT AND RESULT}

We conducted an experiment to evaluate how effectively students learned from the proposed game, as shown in Fig. 1. The experiment included two 2.5-hour classes. Participants in this study were 46 graduate students enrolled in the construction management program offered by the civil engineering department at a public university in Taiwan. The students were randomly divided into two groups: experimental group 
$(n=24)$ and control group $(n=22)$.

In the first class, both the control and experimental groups received 2.5 hours of lecturing on basic construction procurement, followed by a pretest that aimed to ensure homogeneity between the two groups, and to provide data for a comparative baseline for later game-based training. The control group was then divided into several teams. Each performed research or examined a case study on any topic related to construction procurement and negotiation, which is common in traditional educational settings. The experimental group, in contrast, was not engaged in any further activities in the meantime. A month later, while the control group was asked to present their research findings or case studies, the experimental group was instructed to play the proposed game. At the end, both groups were asked to complete a posttest and questionnaire.

The data were analyzed using statistical tests for paired samples. The results were as follows:

1. The pretest scores for the two groups did not differ significantly $(\mathrm{t}=3.161$ and $\alpha=0.072$ ). This implied that the two groups were equivalent.

2. Both groups achieved significantly higher posttest scores compared with pretest scores $(\mathrm{t}=5.751$ and $\alpha<0.001)$. This showed that students improved regardless of the teaching approach.

3. The experimental group, however, showed a greater improvement than the control group (18.27\% vs. $13.59 \%$, respectively). Thus, the gaming approach might yield higher learning efficacy than the traditional one.

We further divided the participants according to their work experience, and observed the following:

1. Students with work experience obtained significantly higher scores than those without work experience, in both the pretest and posttest $(\mathrm{t}=2.447$ and $\alpha=0.018 ; \mathrm{t}=3.717$ and $\alpha=0.001$, respectively). This suggested that the questions included in the tests were practical and field-related.

2. Students with work experience showed significantly greater improvement than those without work experience $(\mathrm{t}=3.808$ and $\alpha=0.001)$. 


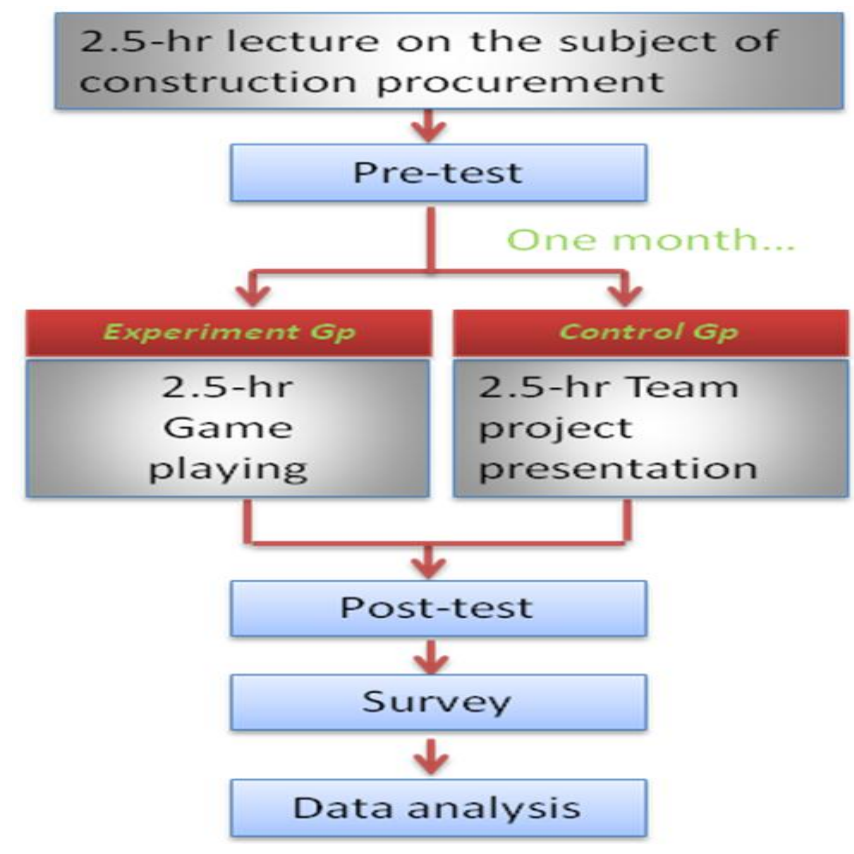

Figure 1 Experiment Design

Table 2 shows the participants' opinions about the course design, learning effectiveness, learning satisfaction, and a comparison with their general experience of traditional teaching. The satisfaction level of the experimental group was significantly greater than that of the control group for all aspects apart from course design. Students in the experimental group reported only $0.39 \%$ more satisfaction with the course design, whereas they reported between $3.66 \%$ and $4.07 \%$ more satisfaction for the remaining three aspects, compared with the control group.

We further analyzed the data by dividing the participants into groups with and without work experience. For participants with little or no work experience, the satisfaction levels of the experimental group were significantly higher than the control group in the constructs of learning effectiveness, learning satisfaction, and a comparison with their general experience of traditional teaching.

Our results showed that the integration of game-playing helped improve students' test scores and learning satisfaction. However, for students with a professional degree or at least three years of work experience, satisfaction levels did not differ significantly between the control and experimental groups. In conclusion, our teaching experiment showed that the proposed educational game is expected to enhance students' procurement 
negotiation skills.

Table 2 Various Dimensions of the Questionnaire Analysis Table

\begin{tabular}{|c|c|c|c|c|c|c|}
\hline Factor dimensions & Group & $\begin{array}{c}\text { \# of } \\
\text { subjects }\end{array}$ & Mean & $\mathrm{SD}$ & $\mathrm{t}$ & $\mathrm{p}$ \\
\hline \multirow{2}{*}{ Course design } & Control & 22 & 3.8148 & 0.48 & \multirow{2}{*}{0.880} & \multirow{2}{*}{0.379} \\
\hline & Experimental & 24 & $+0.39 \%$ & 0.60 & & \\
\hline \multirow{2}{*}{$\begin{array}{l}\text { Learning } \\
\text { effectiveness }\end{array}$} & Control & 22 & 3.6989 & 0.49 & \multirow{2}{*}{$2.142^{*}$} & \multirow{2}{*}{0.039} \\
\hline & Experimental & 24 & $+3.66 \%$ & 0.61 & & \\
\hline \multirow{2}{*}{ Learning satisfaction. } & Control & 22 & 3.7612 & 0.50 & \multirow{2}{*}{$2.045^{*}$} & \multirow{2}{*}{0.042} \\
\hline & Experimental & 24 & $3.9143+4.07 \%$ & 0.65 & & \\
\hline \multirow{2}{*}{$\begin{array}{l}\text { Compared with the } \\
\text { traditional teaching }\end{array}$} & Control & 22 & 3.7844 & 0.44 & \multirow{2}{*}{$2.392^{*}$} & \multirow{2}{*}{0.018} \\
\hline & Experimental & 24 & $3.9329+3.92 \%$ & 0.57 & & \\
\hline
\end{tabular}

\section{REFERENCES}

Brozik, D., \& Zapalska, A. (2002). The portfolio game: Decision making in a dynamic environment. Simulation \& Gaming, 33(2), 242-255. http://dx.doi.org/10.1177/1046878102332013.

Bushell, T. (2001, April). The role of the business game in management education. Paper presented at the of the Conference Reflections on Teaching: Maintaining Quality in Changing Times, Low Wood, Lake Windermer.

Dzeng, R.J., \& Lin, Y.C. (2004). Intelligent agents for supporting construction procurement negotiation. Expert Systems with Applications, 27(1), 107-119. http://dx.doi.org/10.1016/j.eswa.2003.12.006.

Dzeng, R.J., \& Lin, Y.C. (2005). Searching for better negotiation agreement based on genetic algorithm. Computer-Aided Civil and Infrastructure Engineering, 20(4), 280-293. http://dx.doi.org/10.1111/j.1467-8667.2005.00393.

Erdem, M. (2009). Effects of learning style profile of team on quality of materials developed in collaborative learning processes. Active Learning in Higher Education, 10(2), 154-171. http://dx.doi.org/10.1177/1469787409104902.

Liang, T., \& Doong, H. (1999, August). Effects of bargaining in electronic commerce. Paper presented at the International Conference on Advance Issues of E-Commerce and Web-Based Information Systems, Santa Clara, CA.

Mumpower, J.L. (1991). The judgment policies of negotiators and the structure of negotiation problems. Management Science, 37(10), 1304-1324. 
International Journal of Cyber Society and Education 71

http://dx.doi.org/10.1287/mnsc.37.10.1304. 
